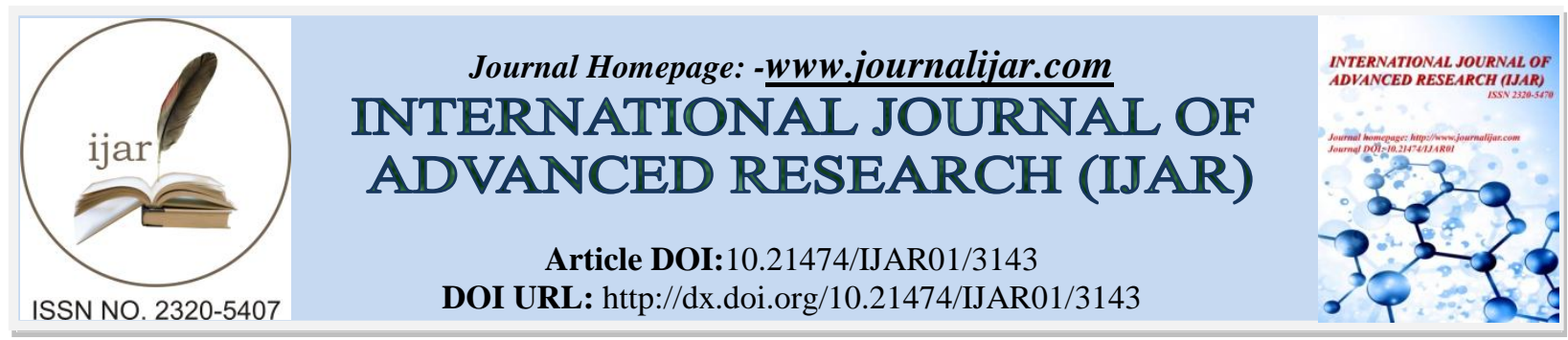

RESEARCH ARTICLE

\title{
GAMMA-RAY TRANSMISSION COEFFICIENTS FOR COMPOUNDS OF SOME BIOMEDICALLY IMPORTANT ELEMENTS
}

\author{
Burcu Akca ${ }^{1 *}$ and Salih Zeki Erzeneoğlu ${ }^{2}$ \\ 1. Computer Engineering, Faculty of Engineering, Ardahan University, Ardahan, Turkey. \\ 2. Department of Physics, Faculty of Sciences, Atatürk University, Erzurum, Turkey.
}

\section{Manuscript Info}

Manuscript History

Received: 16 December 2016

Final Accepted: 17 January 2017

Published: February 2017

Key words:

EDXRF, transmission coefficients,

biomedically important elements

\begin{abstract}
Transmission coefficientsfor compounds of some biomedically important elements ( $\mathrm{Na}, \mathrm{Mg}, \mathrm{Al}, \mathrm{Ca}$ and $\mathrm{Fe}$ ) have been measured by using an extremely narrow collimated-beam transmission method in the energy $59.5 \mathrm{keV}$. Gamma-rays of ${ }^{241} \mathrm{Am}$ passed through compounds were detected with a high-resolution $\mathrm{Si}(\mathrm{Li})$ detector and using energy dispersive X-ray fluorescence spectrometer (EDXRF). Results are presented and discussed in this paper.
\end{abstract}

Copy Right, IJAR, 2017,. All rights reserved.

\section{Introduction:}

The gamma-ray transmission method is important, because give information about light transmittance of material. For example,permeable or less absorbing materials have large transmission coefficients but well absorbing materials have small transmission coefficients. The gamma-ray transmission method is used for many working. Several of these studies are listed. A thickness gauging model of steel plates with build-up treatment, which is based on a gamma-ray transmission technique, has been proposed.It is shown that the calculated values with the new model are in good agreement with experimental data obtained by the gamma-ray thickness gauge in the thickness range from 0 to $10 \mathrm{~cm}$ [1].Gamma-ray transmission methods have been used accurately for the study of the properties of a porous medium such as soil. Different soil parameters are determined by using gamma-ray transmission method. To this end, the soilsamples were collected from various regions of Turkey and a $\mathrm{NaI}(\mathrm{Tl})$ detector measured the attenuation of strongly collimatedmonoenergetic gamma beam through soil samples [2]. X-raytransmission factors of some boron compounds $\left(\mathrm{H}_{3} \mathrm{BO}_{3} ; \mathrm{Na}_{2} \mathrm{~B}_{4} \mathrm{O}_{7}\right.$ and $\left.\mathrm{B}_{3} \mathrm{Al}_{2} \mathrm{O}_{3}\right)$ have been determined byusing an extremelynarrow-collimatedbeam transmission method in the energyrange $15.746-40.930 \mathrm{keV}$ [3]. Measurements of the total porosity of TRe soil, sandstone rocks and porous ceramic samples have been provided. For determination of the total porosity, the gamma-ray transmission method and the Archimedes method (conventional) were employed [4]. Gamma ray transmission measurements have been used to evaluate the water equivalence of solid phantoms. Technetium-99m was used in narrow beam geometry and the transmission of photons measured, using a gamma camera, through varying thickness of the solid phantommaterial and water. Measured transmission values were compared with Monte Carlo calculated transmission data using the EGSnrc MonteCarlo code to score fluence in a geometry similar to that of the measurements [5].Transmission factors of main parameters have been determined that affecting the properties of both normal- and heavy-weight concrete in order to increase knowledge and understanding of radiationattenuation in concrete at a later age. Water/cement (W/C) ratio, curing condition, cement quantityand air entraining agent (AEA) have been selected as the main parameters. Eight energy values have beenselected within the energy interval of $30.85-383.85 \mathrm{keV}$ to be used in the radiation source [6].Gamma-ray transmission method has been applied for studying the properties of cultivated soil. Additionaly, mass attenuation coefficients, bulk density, moisture content.porositv. and field cabacitv have been determined. Five soil samples have been collected from

Corresponding Author:Burcu Akça.

Address: Computer Engineering, Faculty of Engineering, Ardahan University, Ardahan,

Turkey. 
different agriculturezones in Egypt [7]. The change according to the annealing temperature and time of $\gamma$-ray transmission factors or transmissivity of semiconductor crystals have been examined. Gamma rays of Am-241 passed through crystals have been detected by a high-resolution $\mathrm{Si}(\mathrm{Li})$ detector and by using energy dispersive $\mathrm{X}$ ray fluorescence spectrometer [8].

According to the literature, there are not experimental data for transmission coefficients of these compoundsat 59.5 $\mathrm{keV}$ photon energy. Thisstudy presents the first experimental data. The aim of this work isto completesthis lack of the literature and create a basis forother studies.

\section{Theory:}

When $\gamma$-ray beam passes through an absorber, it is attenuated. The degree of attenuation depends on the scattering and various absorption processes. The absorption coefficient $\mu$ can be derived from the Lambert-Beer law

$$
I=I_{0} \cdot e^{-\mu x}
$$

where $I_{0}$ and $I$ are the unattenuated and attenuated photon intensities, respectively,and $\mu\left(\mathrm{cm}^{-1}\right)$ is the linear attenuation coefficient of the material. A narrow beam of monoenergetic photons with incident intensity $I_{0}$, penetrating a layer of material with mass thickness $x$ (mass-per-unit area) and density $\rho$ emerges with intensity Igiven by theexponentialattenuation law,

$$
\frac{I}{I_{0}}=\exp [-\mu x]
$$

where $I / I_{0}$ is the transmission coefficient $(T)$.

\section{Experimental:}

The schematically arrangement of the experimental setup used in the present work is shown in Fig. 1. It consists of a $3.7 \times 10^{9} \mathrm{~Bq}(100 \mathrm{mCi}){ }^{241} \mathrm{Am}$ point source, which essentially emits monoenergetic $(59.5 \mathrm{keV}) \gamma$-rays. The powder samples were compressed into pellets for $10 \mathrm{~s}$ at 15 ton by using a manual hydraulic press. Target had a diameter of $13 \mathrm{~mm}$. The intensities of fluorescent $\gamma$-rays were measured using a high-resolution $\mathrm{Si}(\mathrm{Li})$ detector (FWHM of 160 $\mathrm{eV}$ at $5.96 \mathrm{keV}$ ) and the data were collected into 4096 channels of a multichannel analyzer. The spectra were collected for a period of $1000 \mathrm{~s}$. A typical spectrum of $59.5 \mathrm{keV}$ gamma ray transmissions through $\mathrm{FeCl}_{2}$ is shown in Fig. 2.

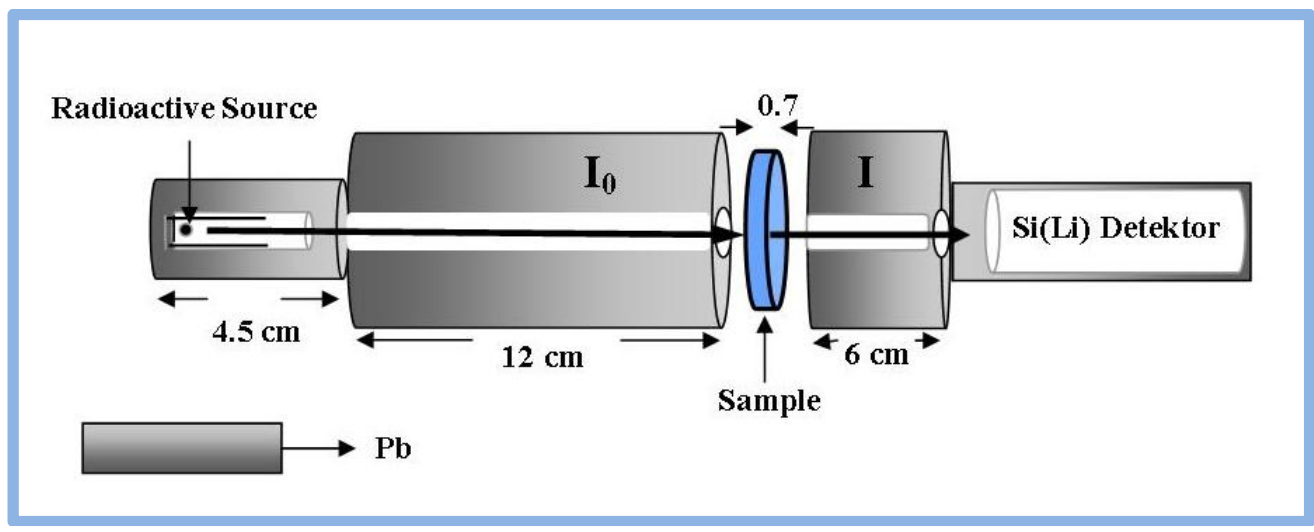

Fig. 1: Experimental geometry. 




Fig. 2: Spectrum of $59.5 \mathrm{keV}$ gamma rays obtained with absorber $\left(\mathrm{FeCl}_{2}\right)$.

\section{Results and Discussion:}

In this study, transmission coefficients for compounds of some biomedically important elements ( $\mathrm{Na}, \mathrm{Mg}, \mathrm{Al}, \mathrm{Ca}$ and $\mathrm{Fe}$ ) have been measured. These compounds can be listed as follows; $\mathrm{NaO}_{2} \mathrm{C}_{2} \mathrm{H}_{3}, \mathrm{NaNO}_{3}, \mathrm{Na}_{2} \mathrm{CO}_{3}, \mathrm{NaF}_{2} \mathrm{Na}_{2} \mathrm{SO}_{4}$, $\mathrm{Na}_{2} \mathrm{SO}_{3}, \mathrm{NaCl}, \mathrm{Mg}\left(\mathrm{NO}_{3}\right)_{2}, \mathrm{MgO}, \mathrm{Al}\left(\mathrm{NO}_{3}\right)_{3}, \mathrm{AlCl}_{3}, \mathrm{CaO}_{6} \mathrm{C}_{6} \mathrm{H}_{10}, \mathrm{CaHPO}_{4}, \mathrm{CaF}_{2}, \mathrm{CaSO}_{4}, \mathrm{Fe}_{2}\left(\mathrm{SO}_{4}\right)_{3}, \mathrm{FeCl}_{3}, \mathrm{FeCl}_{2}$. Transmission coefficients $(T)$ for compounds are given Table 1 . Experimental effective atomic numbers $\left(Z_{\text {eff(Exp) }}\right)$ show second column in the Table 1 [9]. Additionally, experimental effective atomic numbers with the change ofthe transmission coefficients for compounds shown in Fig 3.

In composite materials like alloys, soil, plastic, biological material, and soforth, for photon interactions, the atomic number cannot be represented uniquely acrossthe entire energy region, as in the case of elements, by asingle number.This number in composite materials is called"effective atomic number," and it varies with energy [10]. 
Table 1:Transmission coefficients for compounds of some biomedically important elements

\begin{tabular}{|c|c|c|}
\hline Sample & $Z_{\text {eff(Exp) }}$ & $T$ \\
\hline $\mathrm{NaO}_{2} \mathrm{C}_{2} \mathrm{H}_{3}$ & 5.808 & 0.26138 \\
\hline $\mathrm{NaNO}_{3}$ & 8.086 & 0.90575 \\
\hline $\mathrm{Na}_{2} \mathrm{CO}_{3}$ & 9.450 & 0.91214 \\
\hline $\mathrm{NaF}$ & 9.897 & 0.80288 \\
\hline $\mathrm{Na}_{2} \mathrm{SO}_{4}$ & 11.648 & 0.88468 \\
\hline $\mathrm{Na}_{2} \mathrm{SO}_{3}$ & 12.364 & 0.88144 \\
\hline $\mathrm{NaCl}$ & 14.230 & 0.79087 \\
\hline $\operatorname{Mg}\left(\mathrm{NO}_{3}\right)_{2}$ & 7.921 & 0.90430 \\
\hline MgO & 10.042 & 0.89418 \\
\hline $\mathrm{Al}\left(\mathrm{NO}_{3}\right)_{3}$ & 8.535 & 0.92275 \\
\hline Al & 13.029 & 0.89442 \\
\hline $\mathrm{AlCl}_{3}$ & 14.832 & 0.86498 \\
\hline $\mathrm{CaO}_{6} \mathrm{C}_{6} \mathrm{H}_{10}$ & 6.474 & 0.88790 \\
\hline $\mathrm{CaHPO}_{4}$ & 12.290 & 0.87036 \\
\hline $\mathrm{CaF}_{2}$ & 14.569 & 0.81274 \\
\hline $\mathrm{CaSO}_{4}$ & 15.698 & 0.85019 \\
\hline Ca & 19.317 & 0.78707 \\
\hline $\mathrm{Fe}_{2}\left(\mathrm{SO}_{4}\right)_{3}$ & 15.661 & 0.78193 \\
\hline $\mathrm{FeCl}_{3}$ & 20.537 & 0.78763 \\
\hline $\mathrm{FeCl}_{2}$ & 22.126 & 0.82135 \\
\hline $\mathbf{F e}$ & 26.839 & 0.14101 \\
\hline
\end{tabular}

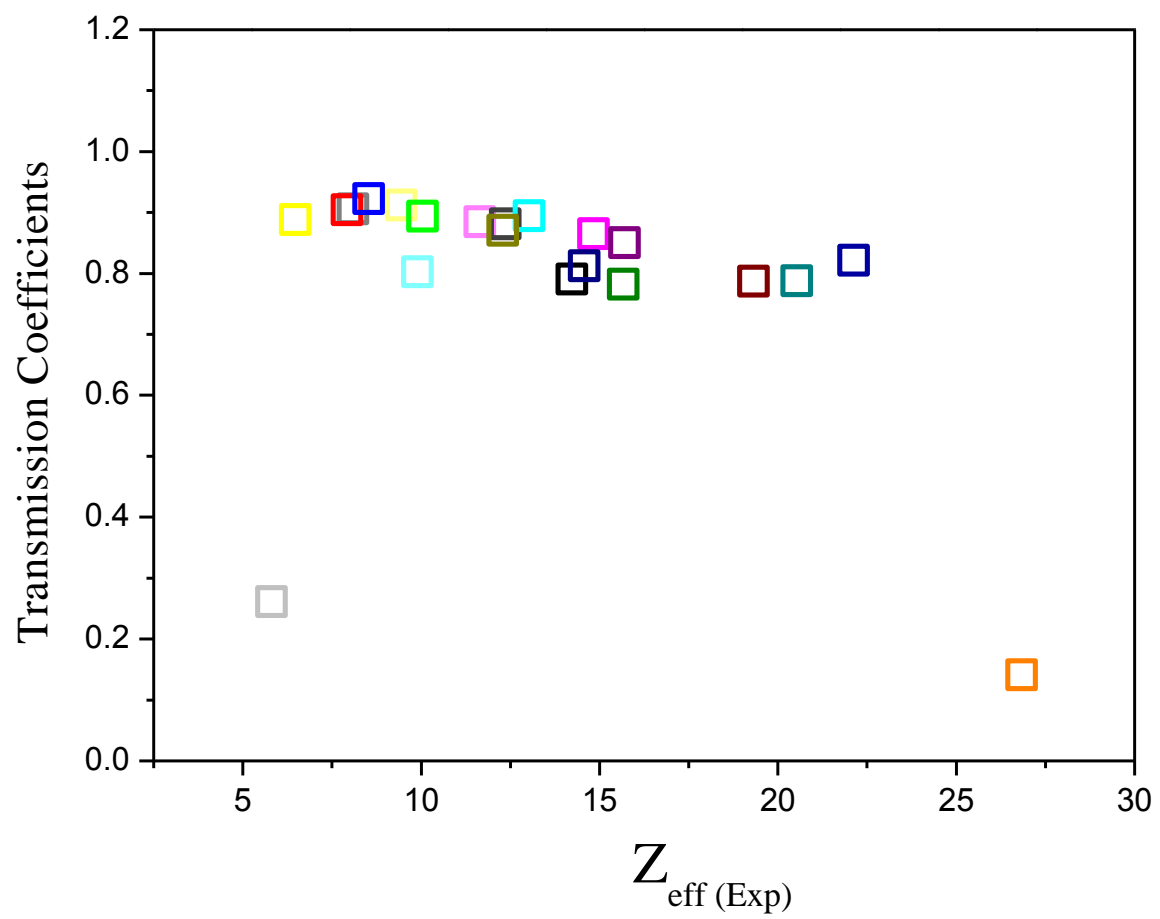

Fig. 3:Transmission coefficients versus experimental effective atomic numbers of compounds. 
In Table 1 and Fig. 3, it is clearly seen that the increase in the effective atomic number with the transmission coefficients of $\mathrm{Na}$ and $\mathrm{Ca}$ compounds a significant change was'nt observed, but transmission coefficients decreased of $\mathrm{Mg}$ and $\mathrm{Al}$ compounds. Unlike them, the transmission coefficients increased for Fe compounds. According to this, $\mathrm{Mg}$ and $\mathrm{Al}$ compounds than Fe compounds have more absorption. So, Fe compounds have more transmittance. We were informed about the light transmittance of these compounds using the $\gamma$-ray transmission method.Furthermore; the method of gamma-ray transmission permits the measurement of several parameters, such as: density, spatial and temporal profiles of moisture and porosity of amorphous materials, and the spatial distribution of the pores in the sample [11].

\section{Conclusions and Suggestions:}

As a result; experimental transmission coefficients for compounds of some biomedically important elementsmore sensitive measurable usedwith an extremely narrow collimated-beam transmission methodin this study.Compounds of biomedically importantcan be used elements in different areas especially as medicine study. In the future, studies can be performeddifferent energies, elements, compounds and experimental geometries. In this way, other studies are created basic and lacking will be eliminated in the literature.

\section{References:}

1. Shirakawa, Y., A build-up treatment for thickness gauging of steel plates based on gamma-ray transmission, 2000, Applied Radiation and Isotopes, 53, 581-586.

2. Baytaş, A. F., Akbal, S. Determination of soil parameters by gamma-ray transmission, 2002, Radiation Measurements 35, 17-21.

3. İçelli, O., Erzeneoğlu S., Boncukcuoğlu, R., Measurement of X-raytransmission factors of some boron compounds, 2003, Radiation Measurements 37, 613 - 616.

4. Apolloni, C. R., Pottker, W. E., Non-destructive porosity profile measurement of amorphous materials by gamma-ray transmission, 2004,Applied Radiation and Isotopes 61, 1133-1138

5. Hill, R. F., Brown S., Baldock, C., Evaluation of thewater equivalence of solid phantoms using gamma ray transmission measurements, 2008,Radiation Measurements 43, 1258 - 1264.

6. Şahin, R., Polat, R. İçelli, O., Çelik, C.,Determination of transmission factors of concretes with different water/cement ratio, curing condition, and dosage of cement and air entraining agent, 2011, Annals of Nuclear Energy 38, 1505-1511.

7. Medhat, M. E., Application of gamma-ray transmission method for study the properties of cultivated soil, 2012, Annals of Nuclear Energy 40, 53-59.

8. Akça, B., Erzeneoğlu, S. Gürbulak, B., Measurement of $\gamma$-ray transmission factors of semiconductor crystals at various annealing temperature and time, 2015, Indian Journal of Pure \& Applied Physics, 53, 49-55.

9. Akça, B., Erzeneoğlu S.Z. The Mass Attenuation Coefficients, Electronic, Atomic, and Molecular Cross Sections, Effective Atomic Numbers, and Electron Densities for Compounds of Some Biomedically Important Elements at $59.5 \mathrm{keV}, 2014$, Science and Technology of Nuclear Installations, 2014, 1-8.

10. Prasad, S. G., Parthasaradhi,K., and Bloomer, W. D., Effective atomic numbers for photoabsorption in alloys in the energyregion of absorption edges, 1998, Radiation Physics and Chemistry, 53, 449-453.

11. Apolloni, C. R., Pottker, W. E., Non-destructive porosity profile measurement of amorphous materials by gamma-ray transmission, 2004, Applied Radiation and Isotopes, 61 ,1133-1138. 